Dicle Tıp Dergisi / Dicle Med J (2019) 46 (1) : 159 - 165

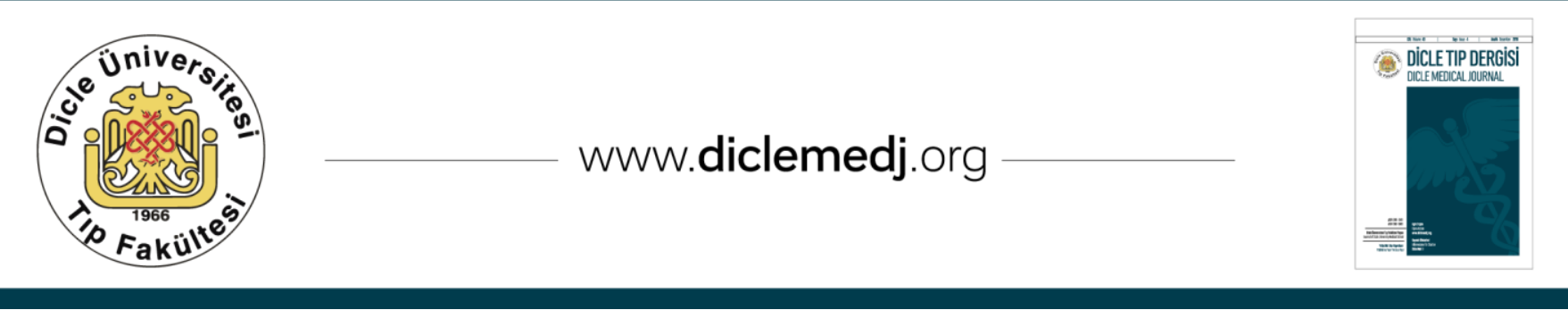

Özgün Araștırma / Original Article

\title{
Katarakt Cerrahisi ile Aynı Seansta Skleral Askılı Göz İçi Lens Yerleștirilmesi
}

\author{
Selahattin Balsak ${ }^{1}$ Zeynep Gürsel Özkurt² \\ 1 Dicle Memorial Hastanesi Göz Hastallkları Birimi, Diyarbakır, Türkiye ORCID: 0000-0002-2269-474X \\ 2 Dicle Üniversitesi Tıp Fakültesi Göz Hastalıkları Anabilim Dalı, Diyarbakır, Türkiye ORCID: 0000-0001-5711-4736
}

Geliş: 16.12.2018; Revizyon: 08.02.19; Kabul Tarihi: 08.02.2019

Öz

Amaç: Bu çalışmada amacımız, ameliyat öncesi zonül veya kapsül zaafiyeti olan ve fakoemülsifikasyon (FAKO) cerrahisi ile aynı seansta skleral askılı göz içi lensi (GíL) yerleştirilmesi yaptığımız hastaların operasyon sonrası oftalmolojik bulgularını değerlendirmektir.

Yöntemler: Ameliyat öncesinde hastaların Snellen eşeli ile görme keskinlikleri ölçüldü, ön ve arka segmentler incelendi, göz içi basınçları aplanasyontonometri ile ölçüldü. Kornea keratometri değerleri otorefraktokeratometre ile K1 ve K2 olarak en dik ve en düz meridyenlerde ölçüldü. Ameliyatta aynı seansta FAKO cerrahisi ile skleral askılı GíL yerleştirilmesi yapıldı. Hastalar en az 6 ay takip edildi.

Bulgular: Çalışmaya 31 hastanın 36 gözü dahil edildi. Olguların 14'ü $(\% 45,1)$ kadın, 17'si $(\% 54,9)$ erkek idi. Yaş ortalaması $51.7 \pm 24.0(25-65)$ yıl idi. Olguların 16 'sında $(\% 44,5)$ pseudoeksfoliasyona 10 'unda $(\% 27,8)$ travmaya ve 10’unda $(\% 27,8)$ MarfanSendromu'na bağlı zonülzaafiyeti vardı. Ortalama görme keskinlikleri ameliyat öncesi $0.1 \pm 0.1$ iken, ameliyat sonrası 6 . ay da $0.6 \pm 0.3$ idi $(p \leq 0.000)$. Göz içi basıncı değerlerinde ameliyat sonrası istatiksel olarak anlamlı düşüș izlendi $(\mathrm{p}=0.036)$. Korneaların $\mathrm{K} 1$ ve K2 değerlerinde ameliyat sonrası değişiklikler istatiksel olarak anlamlı değildi ( $\mathrm{p}=0.351 ; \mathrm{p}=0.875$ sırasıyla). Gözlerin ameliyat sonrası ölçülen sferik değerleri ortalama $+0.50 \pm 0.50 \mathrm{D}$ idi. Ameliyat sırasında olgularda komplikasyona rastlanmadı. Ameliyat sonrası dönemde ise beş $(\% 13,9)$ olguda göz içi basıncı artışı ve iki olguda $(\% 5,5)$ vitre içi kanama oluştu.

Sonuç ve Yorum: Katarakt cerrahisi ile aynı seansta skleral askılı GíL yerleștirilmesi erken görsel rehabilitasyon için önemlidir. Ayni seansta fakoemülsifikasyon ve skleral askılı Gíl yerleştirilmesi ayrı seanslarda yapılan cerrahilere göre komplikasyon oranlarını arttırmamıştır.

Anahtar kelimeler: Fakoemulsifikasyon; Travmatik katarakt; Skleralfiksasyon; Zonül diyalizi; Pseudoeksfoliasyon.

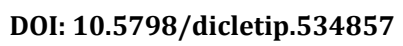

Yazışma Adresi / Correspondence: Selahattin Balsak, Dicle Memorial Hastanesi Göz Hastalıkları Birimi, Diyarbakır, Türkiye e-mail: selahattinbalsak@gmail.com 


\title{
Scleral Fixated Intraocular Lens Implantation at the Same Session with Cataract Extraction
}

\begin{abstract}
Objective: The aim of our study was to evaluate ophthalmologic findings of patients who had preoperative capsullar or zonullar insufficiency and underwent scleral fixated intraocular lens (IOL) implantation at the same session with phacoemulsification surgery.

Method: Preoperatively the patients' visual acuities were measured by Snellen, anterior and posterior segments were evaluated and intraocular pressures were measured by applanation tonometer. Kornealkeratometry values were measured by Topcon KR-800/RM-800 otorefractokeratometry at the stepest and flatest meridians as K1and K2. During the surgries, after cataract extraction scleral fixated IOL was implantated. The patients were followed at least 6 months after the operation.

Results: Thirty six eyes of 31 patients were included. Fourteen patients (45.1\%) were female, seventeen (54.9\%) were male. The average of age was $51.7 \pm 24.0(25-65)$ years. The ethiology was trauma in $10(27.8 \%)$, Marphan Syndrome in $10(27.8 \%)$ and pseudoeksfoliation in $16(44.5 \%)$ of the eyes. Preoperatively the average of best corrected visual acuities with snellen charts were $0.1 \pm 0.1$ and at the postoperative 6th month it was $0.6 \pm 0.3$ with significant improvement $(p \leq 0.000)$. Intraocular pressures decreased significantly $(p=0.036)$. The changes of $K 1$ and $K 2$ kerometric values were not statistically significant $(\mathrm{p}=0.351 ; \mathrm{p}=0.875$ respectively). The average postoperative spheric values were $+0.50 \pm 0.50 \mathrm{D}$. Postoperatively, at five eyes $(13.9 \%)$ intraocular pressure rised slightly, at two eyes $(5.5 \%)$ intravitreal hemoragyoccured.

Conclusion: Scleral fixated IOL implantation at the same session with cataract ekstraction provides rapid visual improvement. In the same session, phacoemulsification and scleral suspension IOL placement did not increase complication rates compared to surgeries performed in separate sessions.
\end{abstract}

Keywords: Phacoemulsification; Traumatic cataract; Scleral fixation; Zonul dialysis; Pseudoexfoliation

\section{GíRIS}

Katarakt cerrahisi tüm dünyada ve ülkemizde en sık uygulanan göz cerrahilerindendir. Ülkemizde yapılan katarakt ameliyatlarında \%73,7 oranında fakoemülsifikasyon (FAKO) ve göz içi merceği (GİL) yerleştirme tekniği uygulanmaktadır. Bu teknik esnasında en sık görülen komplikasyon da arka kapsül yırtılmasıdır ${ }^{1}$.

Arka kapsül yırtılması GíL yerleştirilmesi için yeterli kapsül desteğinin sağlanamaması ile sonuçlanabilmektedir. Ayrıca travma sonrası kapsülü veya zonülleri hasar gören hastalarda, homosistinüri, Marfan ve Weil-Marchesani sendromu gibi kalitsal nedenli veya psödoeksfoliasyon gibi edinsel nedenli zonülzaafiyeti olan hastalarda, katarakt cerrahisi esnasında kapsül içi GIL yerleștirilemeyebilir-5. Yeterli kapsül ve zonül desteği olamayan gözlerde afakinin tedavisi ön kamara GíL, iris kıskaçlı arka kamara GíL veya skleral askılı arka kamara Gİ ile yapılabilmektedir. Günümüzde ön kamara GÍL yerleştirilmesinin uzun vadede ciddi ön kamara komplikasyonlarına yol açtığı bilindiğinden afakinin rehabilitasyonunda arka kamara lensleri tercih edilmektedir ${ }^{6,7}$.

Sağlı alanında teknolojinin ilerlemesi günümüzde hastaların katarakt cerrahisi sonrası görme beklentilerinin artmasına neden olmuştur. Ameliyat öncesi kapsül ve zonülzaafiyeti olduğu tespit edilen hastaların ilk operasyon sonrasinda afak bırakılmalarındansa, katarakt cerrahisi ile aynı seansta GILL yerleştirilmesi hastaların ameliyat sonrası beklentilerinin daha iyi karşılanmasını sağladığı gibi, ikinci bir ameliyatın maddi, tıbbi ve psikolojik yükünden hastayı kurtarmaktadır.

Bu çalışmada amacımız, ameliyat öncesi zonül veya kapsül zaafiyeti olup katarakt cerrahisi ile 
aynı seansta skleral askılı GïL yerleştirilmesi yaptığımız hastaların ameliyat sonrası görme keskinliklerini ve oftalmolojik bulgularını değerlendirmektir.

\section{YÖNTEMLER}

$\mathrm{Bu}$ çalışma Gazi Yaşargil Eğitim ve Araştırma Hastanesi Etik Kurulu tarafından onaylandı. Helsinki Deklerasyonu prensiplerine uygun olarak yürütüldü. Retrospektif olarak yürütülen çalışmamıza 2015-2018 tarihleri arasında Gazi Yaşargil Eğitim ve Araştırma Hastanesi'nde ameliyat öncesinde zonül ve veya kapsül zaafiyeti olduğu belirlenen ve tek cerrah tarafindan (SB) aynı seansta FAKO cerrahisi yapılan ve arka kamaraya skleral askılı GÍL yerleştirilen 31 hastanın 36 gözü dahil edildi.

Ameliyat öncesinde hastaların anamnezindezonül ve kapsül zafiyetine yol açabilen nedenler sorgulandı. Hastaların görme keskinlikleri Snellen eşeli ile ölçüldü. Oftalmolojik muayenede biyomikroskop ile ön ve arka kamaralar incelendi, göz içi basınçları aplanasyontonometri ile ölçüldü. Kataraktan dolayı arka kamarası görülemeyen olgulara oküler ultrasonografi yapıldı. Hastaların kornea keratometri değerleri TopconKR-800/RM-800 ile $\mathrm{K} 1$ ve $\mathrm{K} 2$ olarak en dik ve en düz meridyenlerde ölçüldü ve kaydedildi. Aksiyel uzunlukları oküler ultrasonografi (Echoscan US-4000 / 500, Nidex, USA) ile belirlendi ve SRK II formülü ile ameliyat sonrası emetropi hedeflenerek planlanan skleral askılı GİL'inindioptrisi hesaplandı. Ameliyat sonrası hastaların her kontrolünde görme keskinliği, göz içi basınçları, ön ve arka kamara incelemeleri yapıld ve yine TopconKR800/RM-800 ile kornea keratometri değerleri ölçüldü.

Ameliyat tekniğinde lokal anestezi sonrasında konjonktivalar sağ ve sol gözde saat 2 ve 8 den açıldı. Bu kadranlarda skleraya, limbusa dik olacak şekilde $3 \mathrm{~mm}$ uzunluğunda yarım skleral kalınlıkta kesiler yapıldı. Koterizasyon yaparken limbusa $1 \mathrm{~mm}$ den fazla yaklaşılmadı.
$\mathrm{Bu}$ kesilerden kresent bıçak ile girilerek yine yarım skleral kalınlık seviyesinde kesinin üst ve alt kısımlarında iki adet skleral cep oluşturuldu. Gözlere saat 11 den limbal kesi yapılarak katarakt cerrahisine başlandı. Kapsüloreksisin ardından fakoemülsifikasyon ile kataraktlı lens temizlendi. Ön vitrektomi ile zonül zafiyeti olan kapsül ve sonrasında ön vitre temizlendi. Korneal kesi yeri $6.5 \mathrm{~mm}$ olacak şekilde genişletildi. İki adet PC 9 skleral askı sütürü ile PMMA skleral askılı GİL her iki haptiklerinden sabitlendi ve sütürlerskleradakilimbusa dik olan kesilerin ortasından çıkacak şekilde ve her iki limbustan eşit uzaklıkta olacak şekilde geçirildi. GİL arka kamaraya yerleştirilip sütürler ile gerginliği ayarlandıktan sonra PC 9 sütürler oluşturulan karşılıklı skleral ceplerden iki kez geçirilerek dügüm cebin içinde kalacak şekilde sabitlendi. Korneal kesi yeri 10.0 naylon sütürile,konjonktivalarda 7.0 vicrylsütür ile kapatılarak operasyona son verildi (Şekil 1). Ameliyat sonrasında ilk 1 hafta saat başı, daha sonraki 3 hafta boyunca azaltılarak kesilmek üzere topikalsteroid ve 2 hafta boyunca topikalantibiotik tedavisi verildi. Hastalar 1. hafta, 1 . ay, 3. ay ve 6.ay kontrollerine çağrıldı.

İstatistik analizler için SPSS sürüm 18 (SPSS Inc, Şikago, IL, ABD) yazılımı kullanıldı. Verilerin tanımlayıcı istatistiklerinde ortalama, standart sapma, medyan en düşük, en yüksek, frekans ve oran değerleri kullanıldı. Değişkenlerin dağılımı KolmogorovSimirnov test ile ölçüldü. Bağımlı nicel verilerin analizinde ise Wilcoxon testi kullanıldı. İstatistiksel açıdan p değerinin 0.05'ten küçük olması anlamlı kabul edildi.

\section{BULGULAR}

Çalışmaya 31 hastanın 36 gözü dahil edildi. Olguların tamamına aynı seansta FAKO yöntemi ile katarakt cerrahisi ve skleral askılı GİL yerleştirilmesi yapıldı. Olguların 14'ü $(\% 45,1)$ kadın, 17'si $(\% 54,9)$ erkek idi. Yaş ortalaması $51.7 \pm 24.0$ yıl, yaş aralığı (25-65)yıl idi. Gözlerin 16'sı $(\% 44,4)$ sağ göz ve 20’si 
$(\% 55,4)$ sol göz idi. Olguların 16 'sında $(\% 44,5)$ pseudoeksfoliasyona bağlı zonülzaafiyeti, 10'unda $(\% 27,8)$ travmatikzonul diyalizi ve 10'unda (\%27,8) MarfanSendromu'na bağlı konjenitalzonülzaafiyeti vardı. Olgular en az 6 ay olmak üzere ortalama $12 \pm 6$ aytakip edildi.
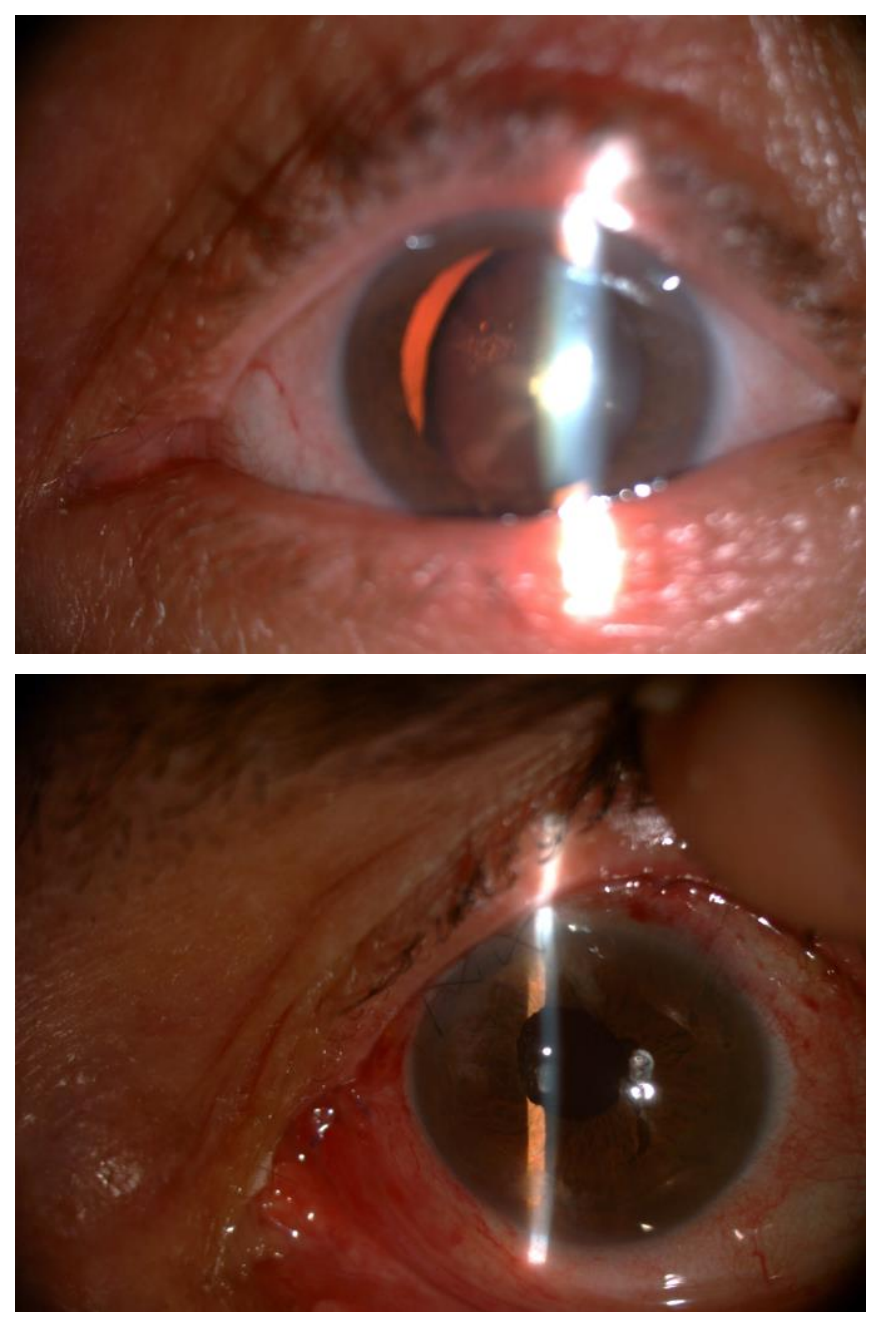

Şekil 1: A: Altmış yaşında kadın hastanın ameliyat öncesi sol gözünün görünümü. Travmaya bağlı saat 8 den 12 ye uzanan zonül diyalizi mevcut. B: Hastanın gözünün ameliyat sonrası 1. hafta görünümü. Saat 11 de 10.0 naylon sütür ile kapatılmış limbal kesi yeri ve santralizeskleral askılı GİL’i izlenmektedir.

Ameliyat öncesi görme keskinlikleri ortalama $0.1 \pm 0.1$ iken, ameliyat sonrası 6 . ay da ortalama görme keskinlikleri $0.6 \pm 0.3$ idi. Ameliyat öncesi ve sonrası görme keskinliklerinde istatiksel olarak anlamlı fark vardı $(\mathrm{p} \leq 0.000)$. Gözlerin 35'inde görme artarken, 1'inde görme aynı kaldı, hiçbir gözde görme azalmadı. Göz içi basıncı (GİB) değerlerinde ameliyat sonrası istatiksel olarak anlamlı düşüş izlendi $(p=0.036)$. Korneaların K1 ve K2 değerlerinde ameliyat sonrası değişiklikler istatiksel olarak anlamlı değildi ( $\mathrm{p}=0.351 ; \mathrm{p}=0.875$ sırasıyla), (Tablo 1). Gözlerin ameliyat öncesi ve sonrası K1 ve K2 değerleri arasındaki fark korneal astigmatizm derecesi olarak hesaplandı. Ortalama astigmat değerleri ameliyat öncesi $1.75 \pm 1.00 \mathrm{D}$, ameliyat sonrasinda ise $2.0 \pm 0.75 \mathrm{D}$ idi $(\mathrm{p}=0.536)$. Dokuz (\%25) gözde astigmat değerleri ameliyat sonrası arttı, $11(\% 30,5)$ gözde azaldı ve $16 \quad(\% 44,5)$ gözde ise değişmedi. Gözlerin tamamının ameliyat öncesi refraksiyonlarınınsferik değeri katarakt mevcudiyetinden ölçülemedi fakat ameliyat sonrası ölçülen sferik değerler ortalama $+0.50 \pm 0.50 \mathrm{D}$ idi.

Tablo 1: Ameliyat öncesi ve sonrası oftalmolojik bulguların dağılımı.

\begin{tabular}{|c|c|c|c|c|}
\hline Bulgular & Min-Mak & Medyan & Ort \pm ss & P değeri \\
\hline \multicolumn{5}{|l|}{ Görme Keskinliği } \\
\hline Ameliyat öncesi & $0.0-0.4$ & 0.0 & $0.1 \pm 0.1$ & \\
\hline Ameliyat sonrası & $0.1-1.0$ & 0.7 & $0.6 \pm 0.3$ & 0.000 \\
\hline \multicolumn{5}{|l|}{ Göz İçi Basıncı } \\
\hline Ameliyat öncesi & $11.0-32.0$ & 14.0 & $15.6 \pm 5.0$ & \\
\hline Ameliyat sonrası & $11.0-24.0$ & 12.0 & $14.2 \pm 3.6$ & 0.036 \\
\hline \multicolumn{5}{|l|}{ K1 Değeri } \\
\hline Ameliyat öncesi & $36.8-45.8$ & 42.8 & $42.5 \pm 2.0$ & \\
\hline Ameliyat sonrası & $37.3-45.0$ & 42.8 & $42.1 \pm 2.0$ & 0.351 \\
\hline \multicolumn{5}{|l|}{ K2 Değeri } \\
\hline Ameliyat öncesi & $39.3-47.5$ & 44.8 & $44.0 \pm 2.3$ & \\
\hline Ameliyat sonrası & $40.0-47.8$ & 44.5 & $44.1 \pm 2.2$ & 0.875 \\
\hline
\end{tabular}

Min-Mak: Minimum-Maksimum Ort \pm ss: Ortalama \pm standart sapma

Olguların ameliyatları sırasında komplikasyona rastlanmadı. Ameliyat sonrası dönemde gelișen ve tedavi ile düzelen geçici komplikasyonlar izlendi. $\mathrm{Bu}$ komplikasyonlar beş $(\% 13,9)$ olguda göz içi basıncı artışı ve iki $(\% 5,6)$ olguda vitre içi kanama idi. Gíl subluksasyonu veya dislokasyonu ise gözlemlenmedi. Hiçbir 
olgumuzda ikinci bir ameliyat gereksinimi olmadl.

\section{TARTIŞMA}

Kataraktlı hastalarda FAKO yöntemi ile lensin temizlenmesi ve aynı seansta kapsül içine GIL yerleștirilmesi günümüzde tercih edilen katarakt cerrahisi yöntemidir. Kapsül ve zonülzaafiyeti olan olgularda ise aynı seansta veya ayrı bir seansta ön kamaraya veya arka kamaraya GİL yerleştirilebilmektedir. Son yıllarda komplikasyonlarının daha az olması nedeniyle arka kamaraya skleraya fiske edilen GİL yerleștirilmesi ön kamaraya GİL yerleştirilmesine oranla daha slk tercih edilmektedir6,7. Skleralfiksasyonlu GíL ler de ön kamara GIL lere göre iridokorneal açı ve korneaya travma yapma ve kornea endotelde yetmezliğe neden olma riskleri çok daha $\operatorname{azd}^{2,8}$. Pseudofakodonezis etkileri azdır ve GIL gözün nodal noktasına daha yakın yerleştiği için refraktif özellikleri daha iyidir6. Pediatrik çağda da kullanılabilmesi çocukluk çağında sık görülebilen travmatik kataraktların rehabilitasyonunda avantaj sağlar ${ }^{9,10}$.

Günümüzde GíL yerleștirilmesinde hedef en az astigmatizm ile hızlı görme rehabilitasyonu sağlamaktır ${ }^{11}$. Çalışmamızda hastaların görmeleri ameliyat sonrası anlamlı artış göstermiş ve $0.6 \pm 0.3$ seviyesine ulaşmıştır. Anlamlı vizyon artışının nedeni hastaların aynı seansta hem katarakt alınması hem de GIL yerleştirilmesi ameliyatlarını olmasıdır. Ameliyat sonrası hastalarımızin K1 ve K2 değerlerinde anlamlı bir değişiklik olmamıș, ameliyat öncesi ve sonrası kornealastigmatizma değerleri sirasıyla $1.75 \pm 1.00 \mathrm{D}$ ve $2.0 \pm 0.75 \mathrm{D}$ olmuştur. Cerrahi sonrası oluşan astigmatizma hedef düzeltilmemiş görme keskinliğini etkilemektedir ${ }^{12}$. Astigmatizma oluşumunu etkileyen faktörler korneal kesinin lokalizisyonu, uzunluğu, sütürasyon tekniği, skleralfleplerin yerleşimi, GIL fiksasyonsütürünün gerginliği ve flepsütürasyon tekniği olarak sıralanabilir. Küçük insizyon ile yapılan katarakt cerrahilerinde temporalinsizyonunsuperiorinsizyona oranla daha az astigmatizma oluşturduğu gösterilmiștir ${ }^{13}$. Çalışmamızdaki cerrahilerde korneal kesimizi saat 11 den temporale doğru $6.5 \mathrm{~mm}$ uzunluğunda ve ayrica santral korneadan dahada uzakta çalışabilmek için şeffaf korneadan değil limbus hizasından açtık. Skleralflep yerine skleral cep oluşturmayı tercih ettiğimiz için daha az koterizasyon ile kanama kontrolü sağladık. Ayrıca skleralkoterizasyondalimbusa $1 \mathrm{~mm}$ den daha fazla yaklaşmamamı skatrizasyona bağlı astigmatizmanin en aza indirilmesini sağlamıștır. Cerrahi sonrası sferik hedef değerler skleral askılı GIL yerleştirilmesi sonrasında, kapsül içi GİL yerleştirilmesine oranla daha fazla sapabilmektedir. Bu sapmalar genellikle hipermetropi yönünde olmaktadır ${ }^{14}$. $\mathrm{Bu}$, skleral askılı GIL' nin, kapsül içi GÍL'ne göre daha posteriorda yerleşebilmesinden kaynaklanabilir. Bizim olgularımızda da ameliyat sonrası ortalama $+0.5 \pm 0.5 \mathrm{D}$ sferikrefraksiyon kalmıștır. Ameliyat öncesi hastaların GILL güçlerini hafif miyopiye göre hesaplamak bu hipermetropik kaymaları en aza indirebilir.

Katarakt cerrahisi ile aynı seansta veya ayrı seansta skleralfiksasyonlu GIL yerleştirilmesinin çeşitli komplikasyon riskleri vardır. Skleralsütürlerinsklera ile birlikte üveadan da geçmesi vakalarda vitre içi hemoraji gelişmesi riskini arttırmaktadır6. Farklı çalışmalarda vitre içi kanama insidanları $\% 4,4$ ila $\% 10$ değerleri arasinda raporlanmıștır 15,16 . Vakalarımızın ikisinde vitre içi kanama gelişmiş ve kanama zaman içinde sorunsuz çekilmiştir. Vitre içi kanama oranımız $\% 5,5$ olup literatür ile uyumlu bulunmuștur. Cerrahi sonrası geçici GIBB artması sadece skleral askılı GíL yerleștirilen vakalarda değil, komplikasyonsuz geçen standart katarakt cerrahilerinden sonra da sık görülebilen bir 
komplikasyondur ${ }^{17}$. Skleral askılı GiL yerleştirilmesinden sonra \%20 ile \%21 GïB artışı bildiren çalışmalar vardır ${ }^{18,19}$. Bizim çalışmamızda ise beş $(\% 13,9)$ hastada geçici GiB artışı olmuş ve topikal tedavilere yanıt alınmıştır.

Cerrahi işlemin kapsül içine veya ön kamaraya GİL yerleștirilmesine göre daha uzun sürmesi ve sütürlerinskleradan geçmesi endoftalmi riskini arttırmaktadır. Buyukortop ve arkadaşlarının skleralfiksasyonlu GIL yerleştirdikleri 103 hastalık serilerinde endoftalmiinsidansını \%1,9, benzer bir başka çalışmada da \%2 olarak bildirmişlerdir ${ }^{18,20}$. Bizim çalışmamızda endoftalmi olan vakamız olmamıștır. İkincil glokom, hifema, kronik intraokülerinflamasyon, retina dekolmanı, kistoidmaküler ödem, sütür erozyonu ve skleralflepatrofisi, GíL desantralizasyonu diğer olası komplikasyonlardır16,18,20. Bizim vaka serimizde bu komplikasyonlara da rastlanmamıştır. Endoftalmi ve diğer komplikasyonların görülmemesi nispeten vaka sayımızın az olması ile açıklanabilir.

Sütürsüzskleralfiksasyonlu GİL yerleştirilmesi ilk kez 1997 yılında tanımlanmıştır ${ }^{21}$. Bu teknik sütüre bağlı komplikasyonları önlense de GíL'nindislokasyon riski fazladır ${ }^{22}$. Ayrıca günümüzde katlanabilir skleral askılı GíL kullanımı ve buna ait çalışmalar da giderek artmaktadır. Katlanabilir skleral askılı GIL kullanıldığında daha küçük korneal kesi açılmakta, ameliyat sonrası hipotoni riski azalmakta ve iyileşme süresi kısalmaktadır ${ }^{23}$. Ayrıca kesi küçük olduğu için ameliyat sonrası astigmatizma da daha az olmaktadır. Şahin ve arkadaşlarının yapmış olduğu çalışmada sert ve katlanabilir skleral askılı GIL yapılan hastaları karşılaştırmışlar ve katlanabilir GíL kullanılanlarda daha az komplikasyon ve daha iyi görsel sonuçlar rapor etmişlerdir ${ }^{19}$.

Zonül ve kapsül zafiyeti olan olgularda en uygun Gíl yerleştirilmesi zamanına ait literatür deprospektif randomize çalışma bulunmamaktadır. Ancak retrospektif olarak yapılan çalışmalarda, skleralfiksasyonluGíL'nin ilk seansta veya başka bir seansta yerleştirilmesinin görsel sonuçlar ve komplikasyon oranları açısından farklı olmadığı gösterilmiştir 24-25. Bizim çalışmamızda da ameliyat sonrası görsel sonuçlar ve komplikasyonlar ayrı seanslarda skleral askılı GíL yerleștirilen çalışmalar ile farklı bulunmamıştır.

Hastaların cerrahi sonrası beklentilerin giderek arttığ bu dönemde katarakt cerrahisi ile aynı seansta skleral askılı GİL yerleştirilmesi erken görsel rehabilitasyon için önemlidir. Ayrıca iki seansta yapılan cerrahiye göre komplikasyon gelişme riski ve ekonomik giderler daha az olmaktadır. Fakat aynı seansta skleral askılı GíL yerleştirmenin belirli bir cerrahi deneyim gerektirdiği de unutulmamalıdır.

Çıkar Çatışması Beyanı: Yazarlar çıkar çatışması olmadığını bildirmişlerdir.

Finansal Destek: Bu çalışma her hangi bir fon tarafından desteklenmemiştir.

Declaration of Conflicting Interests: The authors declare that they have no conflict of interest.

Financial Disclosure: No financial support was received.

\section{KAYNAKLAR}

1. Mete M, Doğan M, Kaya V, et all. Katarakt Anketi 2003. Glo-Kat. 2006; 1: 209-13.

2. Totan Y, Erdurmuş M, Yağcl R. Saydam lens subluksasyonu olan çocuklarda Artistan iris kıskaçlı afakik göz içi lens implantasyonu. Turk J Ophthalmol 2009; 39: 111-4.

3. Gross JG, Kokame GT, Weinberg DV. Dislocated in-theBagIntraocular Lens StudyGroup. In-the-bagintraocular lens dislocation. Am J Ophthalmol. 2004; 137: 630-5.

4. Jensen AD, Cross HE, Paton D. Ocular complications in theWeil-Marchesanisyndrom. Am J Ophthalmol. 1974; 77: 261-9. 
5. Cross HE, Jensen AD. Ocular manifestation in the Marfan Syndrome And Homocystinuria. Am J Ophthalmol. 1973; 75: 405-20.

6. Dick HB, Augustin AJ. Lens implant selection with absence of capsular support. Curr Opin Ophthalmol. 2001; 12: 47-57.

7. Evereklioğlu C, Er H, Bekir NA, et all. Comparison of secondary implantation of flexibleopenloopanteriorchamberandscleral-

fixatedposteriorchamberintraocularlenses. J Cataract Refract Surg. 2003; 29: 301-8.

8. Solomon K, Gussler JR, Gussler C, et all. Incidence and management of complications of transscleral ly sutured posterior chamber lenses. J Cataract Refract Surg. 1993; 19: 488-93.

9. Ganesh A, Bialasiewicz AA, Al-Zuhaibi SM, et all. Visual rehabilitation buy scleral fixation of posterior chamberin traocularlenses in amblyo picap hakic children. Middle East Afr J Ophthalmol. 2008; 15: 61-5.

10. Yurdakul NS, Maden A. Afak çocuklarda sekonder göz içi lens implantasyonu. Turk J Ophthalmol. 2010; 40: 295-9.

11. Rainer G, Menapace R, Vass C, et all. Cornealshapechangesaftertemporalandsuperolateral3. $0 \mathrm{~mm}$ clearcornealincisions. J CataractRefractSurg. 1999; 25: 1121-6.

12. Barequet IS, $\mathrm{Yu} \mathrm{E}$, Vitale $\mathrm{S}$, et all. Astigmatismoutcomes of horizontal temporal versus nasal clear corneal incision cataract surgery. J Cataract Refract Surg. 2004; 30: 418-23.

13. Mallik VK, Kumar S, Kamboj R, et all. Comparison of astigmatism following manual small incision cataract surgery: superior versus temporal approach. Nepal J Ophthalmol. 2012; 4: 54-8.

14. Stem MS, Todorich B, Woodward MA, et all. ScleralFixatedIntraocular Lenses: Pastand Present. J Vitreoretin Dis. 2017; 1: 144-52.
15. Kjeka O, Bohnstedt J, Meberg K, et all. Implantation of scleral fixated posterior chamber intraocular lenses in adults. Acta Ophthalmol. 2008; 86: 537-42.

16. Kutucu P, Sarıcaoğlu S, Recep ÖF, ve ark. Lens luksasyonların daskleral fiksasyonlu göz içi lens implantasyonu. Turk J Ophthalmol. 2009; 39: 177-82.

17. Balsak S, Kaydu A, Erdem S, et all. Brimonidinetimololversusbrinzolamide-timololfortreatment of elevated intraocular pressure after phacoemulsification surgery. Int Ophthalmol. 2018; 38: 1583-9.

18. Türk A, Mollamehmetoğlu S, Erdöl H, ver ark. Skleralfiksasyonlu arka kamara göz içi lens implantasyonu sonuçları. Glo-Kat. 2011; 6: 149-54.

19. Şahin A, Kamış Ü, Oltulu R, ve ark. Skleralfiksasyonlu göz içi lens implantasyonu sonuçlarımız. Selçuk Tıp Derg. 2009; 25: 144-9.

20. Büyükortop N, Alp MN, Kural G. Skleralfiksasyonlu arka kamara lensi implantasyonu: Etyoloji ve cerrahi zamanlama yönünden güvenirlik ve görsel başarı. GloKat. 2006; 1: 47-52.

21. Maggi R, Maggi C. Suturlessscleralfixation of intraocularlenses. J Cataract Refract Surg. 1997; 23: 1289-94.

22. Kumar DA, Agarwal A, Agarwal A, et all. Longtermassessment of tilt of gluedintaocularlenses: an optical coherence tomography analysis 5 yearsaftersurgery. Ophthalmology. 2015; 122: 48-55.

23. Kaynak S, Ozbek Z, Pasa E, et all. Transscleralfixation of foldableintraocularlenses. J Cataract Refract Surg. 2004; 30: 854-57.

24. Lee VY, Yuen HK, Kwok AK. Comparison of outcomes of primary and secondary implantation of scleral fixated posterior chamber intraocular lens. $\mathrm{Br} \mathrm{J}$ Ophthalmol. 2003; 87: 1459-62.

25. Yaniz-Akkaya Z, Burcu A, Uney GO, et all. Primary And Secondary Implantation of scleral- fixated posterior chamber intraocular lenses in adultpatients. Middle East Afr J Ophthalmol. 2014; 21: 44-9. 